University of Nebraska - Lincoln

DigitalCommons@University of Nebraska - Lincoln

Publications, Agencies and Staff of the U.S.

Department of Commerce

U.S. Department of Commerce

2007

\title{
BLUE WHALE VISUAL AND ACOUSTIC ENCOUNTER RATES IN THE SOUTHERN CALIFORNIA BIGHT
}

\author{
Erin M. Oleson \\ University of California - San Diego, eoleson@ucsd.edu \\ John Calambokidis \\ Cascadia Research Collective \\ Jay Barlow \\ NOAA Fisheries, jay.barlow@noaa.gov \\ John A. Hildebrand \\ University of California - San Diego
}

Follow this and additional works at: https://digitalcommons.unl.edu/usdeptcommercepub

Part of the Environmental Sciences Commons

Oleson, Erin M.; Calambokidis, John; Barlow, Jay; and Hildebrand, John A., "BLUE WHALE VISUAL AND ACOUSTIC ENCOUNTER RATES IN THE SOUTHERN CALIFORNIA BIGHT" (2007). Publications, Agencies and Staff of the U.S. Department of Commerce. 299.

https://digitalcommons.unl.edu/usdeptcommercepub/299

This Article is brought to you for free and open access by the U.S. Department of Commerce at DigitalCommons@University of Nebraska - Lincoln. It has been accepted for inclusion in Publications, Agencies and Staff of the U.S. Department of Commerce by an authorized administrator of DigitalCommons@University of Nebraska - Lincoln. 


\title{
BLUE WHALE VISUAL AND ACOUSTIC ENCOUNTER RATES IN THE SOUTHERN CALIFORNIA BIGHT
}

\author{
ERIN M. OLESON \\ Scripps Institution of Oceanography, \\ University of California San Diego, \\ 9500 Gilman Drive 0205, \\ La Jolla, California 92093, U.S.A. \\ E-mail: eoleson@ucsd.edu \\ JOHN CALAMBOKIDIS \\ Cascadia Research Collective, \\ 218 1/2 West 4th Avenue, \\ Olympia, Washington 98501, U.S.A. \\ JAY BARLOW \\ NOAA Fisheries, \\ Southwest Fisheries Science Center, \\ 8604 La Jolla Shores Drive, \\ La Jolla, California 92037, U.S.A. \\ JOHN A. HiLDEBRAND \\ Scripps Institution of Oceanography, \\ University of California San Diego \\ 9500 Gilman Drive 0205, \\ La Jolla, California 92093, U.S.A.
}

\begin{abstract}
The relationship between blue whale (Balaenoptera musculus) visual and acoustic encounter rates was quantitatively evaluated using hourly counts of detected whales during shipboard surveys off southern California. Encounter rates were estimated using temporal, geographic, and weather variables within a generalized additive model framework. Visual encounters $(2.06$ animals $/ \mathrm{h}, \mathrm{CV}=0.10)$ varied with subregion, Julian day, time of day, and year. Acoustic encounters of whales producing pulsed A and tonal B call sequences (song; 0.65 animals $/ \mathrm{h}, \mathrm{CV}=0.06$ ) varied by Julian day, survey mode (transit or stationary), and subregion, and encounters of whales producing downswept $(\mathrm{D})$ calls $(0.41 \mathrm{animals} / \mathrm{h}, \mathrm{CV}=0.09)$ varied by Julian day and the number of animals seen. Inclusion of Julian day in all models reflects the seasonal occurrence of blue whales off southern California; however, the seasonal peak in visual encounters and acoustic encounters of $\mathrm{D}$ calling whales (July-August) was offset from the peak in acoustic encounters of singing whales (August-September). The relationship between visual and acoustic encounter rates varied regionally, with
\end{abstract}


significant differences in several northern regions. The number of whales heard D calling was positively related to the number of animals seen, whereas the number of singing whales was not related to visual encounter rate.

Key words: blue whale, Balaenoptera musculus, visual survey, acoustic survey, encounter rate, feeding ground.

Estimates of cetacean abundance are often based on detection of animals during visual line-transect surveys (Buckland et al. 2001); however, the probability of detecting an animal may vary in different environments or during different seasons. For example, spatial and temporal variability in encounter rates arise when a species seasonally aggregates near certain oceanographic features (Forney and Barlow 1998, Forney 2000, Ferguson and Barlow 2001, Ferguson et al. 2006). Further, bias may arise in line-transect estimates due to whale behavior if the behavior inhibits or enhances the probability of visual detection. Variation in encounter rates may cause bias in abundance estimates if the factors affecting detection are not understood. The addition and integration of surveys using alternative methods of animal detection may reduce this uncertainty. Acoustic monitoring during cetacean surveys provides an alternative method of detection for vocal species. Although limited to vocalizing animals, acoustic monitoring can often detect animals at greater distances and while animals are underwater. Dual-mode surveys, or those including simultaneous visual and acoustic observation, can increase the probability of detection by visually detecting quiet animals and acoustically detecting vocal animals whose behavior may inhibit visual detection.

Although simultaneous visual and acoustic surveys for cetaceans are becoming more common, few have compared the detection rates from these methods, particularly with respect to temporal, geographic, and environmental factors. Dual-mode surveys for delphinids and sperm whales (Physeter macrocephalus) often have acoustic detection rates equal to or higher than visual sighting rates (Thomas et al. 1986, Akamatsu et al. 2001, Mellinger and Barlow 2003, Barlow and Taylor 2005). Higher acoustic than visual detection rates for sperm whales has been attributed to behavioral factors, such as the whales' long dive duration and constant clicking while submerged (Barlow and Taylor 2005). Surveys for baleen whales have often been opportunistic, preventing quantitative comparison of visual and acoustic encounter rates. Dual-mode shipboard surveys of blue (Balaenoptera musculus) and humpback (Megaptera novaeangliae) whales reported higher acoustic than visual encounter rates (Clark and Fristrup 1997, Swartz et al. 2003); however, neither behavioral nor environmental factors were considered.

Recent behavioral studies of vocal eastern North Pacific blue whales indicate that call types may be correlated with behavior (Oleson et al. 2007). The authors found that the production of long-duration, low-frequency, stereotyped sequences, or song, consisting of pulsed $\mathrm{A}$ and tonal $\mathrm{B}$ calls were produced by traveling males, and more variable downswept $\mathrm{D}$ calls were produced by both sexes generally during short breaks from feeding. These behavioral associations may impact the observer's ability to visually detect blue whales producing certain call types, potentially creating bias in abundance estimates. For example, although traveling blue whales may surface more often than foraging blues whales, they spend one-third to one-half the time at the surface than do foraging whales (Acevedo-Gutierrez et al. 2002). This may result in a decreased probability of visual detection of traveling whales. Based on the behavioral correlations observed, singing male blue whales may have a higher 
probability of being missed during visual line-transect surveys. This bias may vary by season if blue whale singing behavior is correlated with the breeding season as has been observed for other baleen whale species, such as humpback whales (Payne and McVay 1971). Similarly, a sex bias in call production and seasonal increases in calling related to mating behavior may impact acoustic detection, introducing variability into estimates of abundance based solely on acoustic surveys.

To identify the most significant sources of variability in blue whale visual and acoustic encounter rates on their southern California feeding grounds, we evaluated the dependence of encounter rates on spatial and temporal variables $(e . g$. ., month, year, time of day, subregion) within a generalized additive model (GAM) framework. Evaluated within each encounter rate model were hourly counts of visually encountered and acoustically encountered whales from dual-mode surveys conducted in the Southern California Bight. Separate acoustic encounter rate models were built for blue whales producing $\mathrm{AB}$ song or $\mathrm{D}$ calls to determine if the detection of these call types is predicted by different temporal or geographic variables. Our findings provide direction for future studies of the relationship between acoustic and visual encounter rates and the development of better methods of assessing blue and other baleen whale distribution and abundance. Understanding the relationships between blue whale visual and acoustic encounter rates is necessary to evaluate the effectiveness of each survey type and to develop methods of abundance estimation based on both detection modes. This will be particularly important for the development and interpretation of fixed-point acoustic surveys for abundance estimation.

\section{METHODS}

\section{Field Methods}

Shipboard surveys for blue whales were conducted bimonthly, from April through November, of 2000 through 2003 aboard the 38 m R/V Robert Gordon Sproul. Each cruise lasted 4-10 d, for a total of 414 effort hours. The cruises combined multiple tasks, including photo identification, tissue sampling, and tagging studies, occasional deployment of oceanographic instrumentation, and a dual-mode visual and acoustic survey. The ship's path was determined by (1) the need to deploy instruments in certain regions (Cortez and Tanner Banks) and (2) the presumed or known distribution of blue whales based on recent sighting reports from whale watch operators or other researchers. For these reasons, track lines were not determined prior to sailing, nor were they equally distributed throughout the study area. In particular, there was less effort in 2003, primarily impacting the northern regions of the study area.

A team of observers maintained a watch for blue whales from a height of $5.6 \mathrm{~m}$ above the water during most daylight hours. The survey was conducted in one of two survey modes (transit or stationary) determined by the movement of the ship. During transit periods, two observers scanned ahead to abeam of the ship using 7 $\times 50$ power binoculars and unaided eyes. A third observer also scanned for whales and recorded sightings and weather conditions (visibility, Beaufort sea state) every $30 \mathrm{~min}$ or when conditions changed. The direction and distance to each marine mammal sighting was noted using the ship's gyro and reticle binoculars. When the blows of large whales were seen, the ship was diverted to their position for species identification. Each individual in a group was identified to species. Upon 
identification of blue whales, we occasionally initiated photo-ID and biopsy studies, and survey effort shifted from transit to stationary mode. Individual blue whales were tracked when the ship was stationary by monitoring dive intervals and surface positions. Infrequently, large aggregations of whales prevented visual tracking of individuals when the ship was stationary. During those periods observers conducted 5 or 10 min scans and counted only unique surfacings. These scans were repeated every $20-30 \mathrm{~min}$ and were averaged for each hour. There is more stationary effort in the afternoon because of the occasional shift to stationary effort when sightings occurred. The use of scan counts during some hours of stationary effort may have introduced variability into our encounter rate estimates; however, it is likely that the degree of variation is much less than that we would have suffered if we had attempted to continuously track all individual blue whales within large aggregations.

Acoustic monitoring for calling blue whales occurred during daylight hours using directional fixing and ranging (DIFAR) sonobuoys (SSQ-53B or 53D) capable of providing the bearing to received sounds between 10 and $2500 \mathrm{~Hz}$. Sonobuoy hydrophones deployed to a depth of $90 \mathrm{ft}(27.4 \mathrm{~m})$. The sonobuoy receiving and recording system consisted of a ship-mounted receiving antenna, calibrated ICOM$\mathrm{R} 100$ radio receivers, and a digital audio tape (DAT) or hard disk to record incoming sound. The receiving and recording system had a flat frequency response from 20 $\mathrm{Hz}$ to $20 \mathrm{kHz}$. The response of the DAT was not flat below $20 \mathrm{~Hz}$, slightly reducing the recording sensitivity at the fundamental frequencies of the blue whale $\mathrm{A}$ and $\mathrm{B}$ calls near $16 \mathrm{~Hz}$. However, these components were still visible in the spectrogram display and easily identifiable due to the presence of higher frequency harmonics. The hardware setup has been described in detail elsewhere (McDonald et al. 2001, Swartz et al. 2003). Acoustic signals were monitored at sea using the software program ISHMAEL (Mellinger 2002). When a call was detected in the spectrographic display, the call was extracted and the bearing to the sound source was estimated using the DIFAR directional components (McDonald 2004). Blue whales producing $\mathrm{AB}$ songs were easily tracked over time through the continuity of received call levels, the similarity of bearing angles, and the consistent timing of song sequences. Tracking of individual singers allowed us to count the number of whales producing $\mathrm{AB}$ song. The number of whales producing $\mathrm{D}$ calls was estimated by counting the number of unique bearing angles occurring in each hour. Because type $\mathrm{D}$ calls are produced intermittently and may occur as counter-calls between closely spaced animals (McDonald et al. 2001, Oleson et al. 2007), the number of whales producing this call type is likely underestimated. Occasionally calls were missed during processing for bearing angle, preventing us from counting individual calls. Song and singular A and B calls have similar frequency and duration characteristics (Oleson et al. 2007). Because of the infrequent nature of singular AB calls it was difficult to distinguish these callers from animals producing song, especially when several singing whales were present. For this reason, we did not count the number of whales producing singular A or B calls, and this call type is not represented in our analysis.

On a few occasions individual blue whales were visually or acoustically detected following a cue from the other survey method. When a cue from one method resulted in detection in the other, the second detection was not included in the analysis. In these cases, the detection was attributed to the first method of contact. Concurrent observations were only included if they were independently detected through both methods. 


\section{Analytical Methods}

Blue whale visual and acoustic counts were summarized hourly and were associated with other variables describing the ship's speed, geographic location, start time of each hour, and the sighting conditions during that hour. Periods of concurrent monitoring less than $1 \mathrm{~h}$ were excluded from the analysis. The blue whale visual encounter rate was calculated as the number of individual whales seen per hour, irrespective of group size. Blue whale acoustic encounter rate was estimated as the number of whales heard producing each call type ( $\mathrm{AB}$ song or $\mathrm{D}$ ) per hour, as described above. The number of hours spent at different times or places was used to describe our survey effort, such that the term "effort" will refer to effort hours in a particular situation. Because the probability of detecting a blue whale may change at different survey speeds, each effort hour was defined according to the average transit speed during that hour. Transit distances during each hour were estimated using the straight-line distance between hourly start and endpoints, and the average transit speed was calculated from these measures. Average transit speed was also represented as a categorical variable where hourly speeds less than $5 \mathrm{nmi} / \mathrm{h}$ were categorized as "stationary" and those greater than $5 \mathrm{nmi} / \mathrm{h}$ as "transit." Both the categorical survey mode and the continuous transit speed descriptions of the ship's movement were available during model selection. Time of day (in Pacific daylight time), month, Julian day, and year were also associated with each hourly segment. Year was included as a categorical variable because effort was not consistent among years, and we were not testing for annual trends in encounter rate. Time of day is included to account for changes in the type of survey effort throughout the day and is not intended to describe hourly changes in detection based on whale behavior. Regional scale variability in the distribution of blue whales may impact encounter rate estimates if not accounted for. Geographic variability in encounter rate was evaluated by subdividing the Southern California Bight in two ways: first into north-south regions delineated at $33.5^{\circ} \mathrm{N}$, and second, into nine subregions (Fig. 1). The north-south subdivision was included because a map of blue whale sightings indicated that there were more whales seen in the northern half of the study area. However, the possibility for smaller-scale variability was evident, leading to the further division of the study area into nine subregions. These subregions were defined subjectively based on the continuity of bathymetry, islands, and the distribution of effort. Both subdivisions were available as regional categories during model selection.

Blue whale encounter rates were modeled using nonparametric GAMs because the functional form of the relationships was not known for any of the explanatory variables. GAMs are extensions of generalized linear models (GLMs), such that the additive predictors need not be constrained to linear functions and may instead include nonparametric smooth functions of the predictors (Hastie and Tibshirani 1990). The link function $g(\mu)$ of a GAM, similar to that of a GLM, relates the mean of the response variable given the predictor variables, $\mu=E\left(Y \mid X_{1}, \ldots, X_{p}\right)$, to the additive predictor:

$$
g(\mu)=\alpha+\sum_{j=1}^{p} f_{j}\left(X_{j}\right)
$$

(Hastie and Tibshirani 1990). Counts of sightings or acoustic detections per hour approximate a Poisson distribution. Therefore, encounter rate was modeled using a 


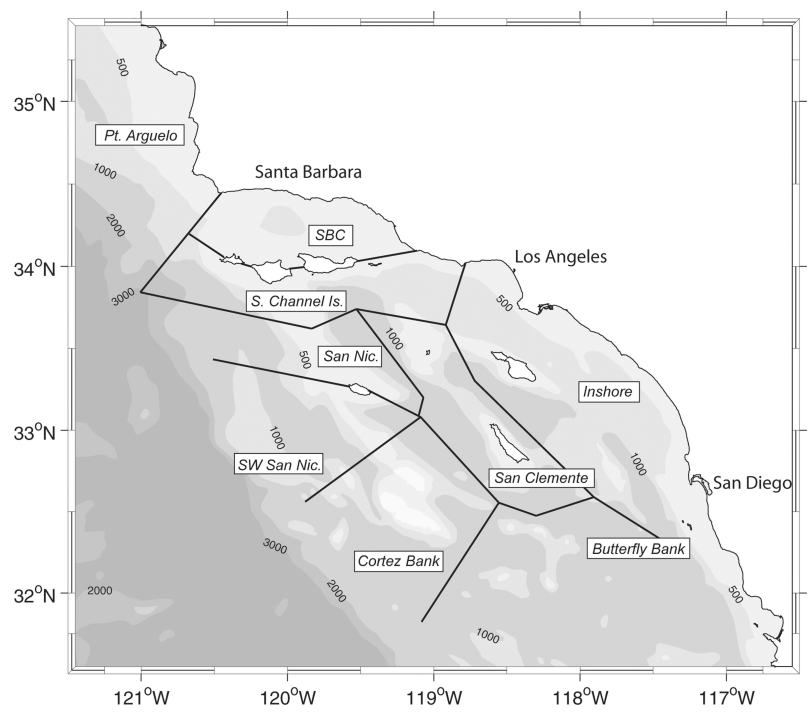

Figure 1. Southern California Bight study area. The nine subregions used in model selection are shown overlaid on the bathymetric contours. A north-south division (not shown) at $33.5^{\circ} \mathrm{N}$ was also used during model selection. That division was not chosen in any of the encounter rate models. $\mathrm{SBC}=$ Santa Barbara Channel.

quasi-likelihood error distribution with variance proportional to the mean and using a logarithmic link function. The logarithmic link function also allows us to model multiplicative effects using additive models

Three GAMs of blue whale encounter rate were built based on the hourly survey data: visual encounters, acoustic encounters of whales producing AB song, and acoustic encounters of whales producing D calls. Each model was built to take advantage of the full extent of the survey data, including stationary periods in high blue whale density regions. The models were built based on the spatial, temporal, and survey variables described in Table 1. A null model for each detection type was built based solely on the mean value of the response variable. The null model was then used in the forward-backward stepwise selection procedure implemented by the software S-Plus (Insightful Corp., Seattle, WA, USA). This procedure evaluated the improvement of model fit with the addition of each predictor variable. The forward-backward stepwise selection procedure also allows evaluation of several forms of individual predictors. For example, during model selection, the super-variable "Region" was evaluated as the two-way north-south division, the nine-way subdivision, or not present in the model. In this way, continuous and ordinal variables could be classified with various smoothing spline fits, allowing the model to choose among several forms of a particular predictor to produce a best-fit model. Initial models were developed using only smoothing splines and linear fits for each continuous predictor variable. Smoothing splines were limited to three degrees of freedom to allow for nonlinear effects while restricting unrealistic detail in the shape of the function. Akaike's information criterion (AIC) was used to determine the best-fit model (Akaike 1973).

Reduction of models to parametric forms is advantageous for the quantitative explanation of encounter rate, as nonparametric spline fits of predictor variables cannot 


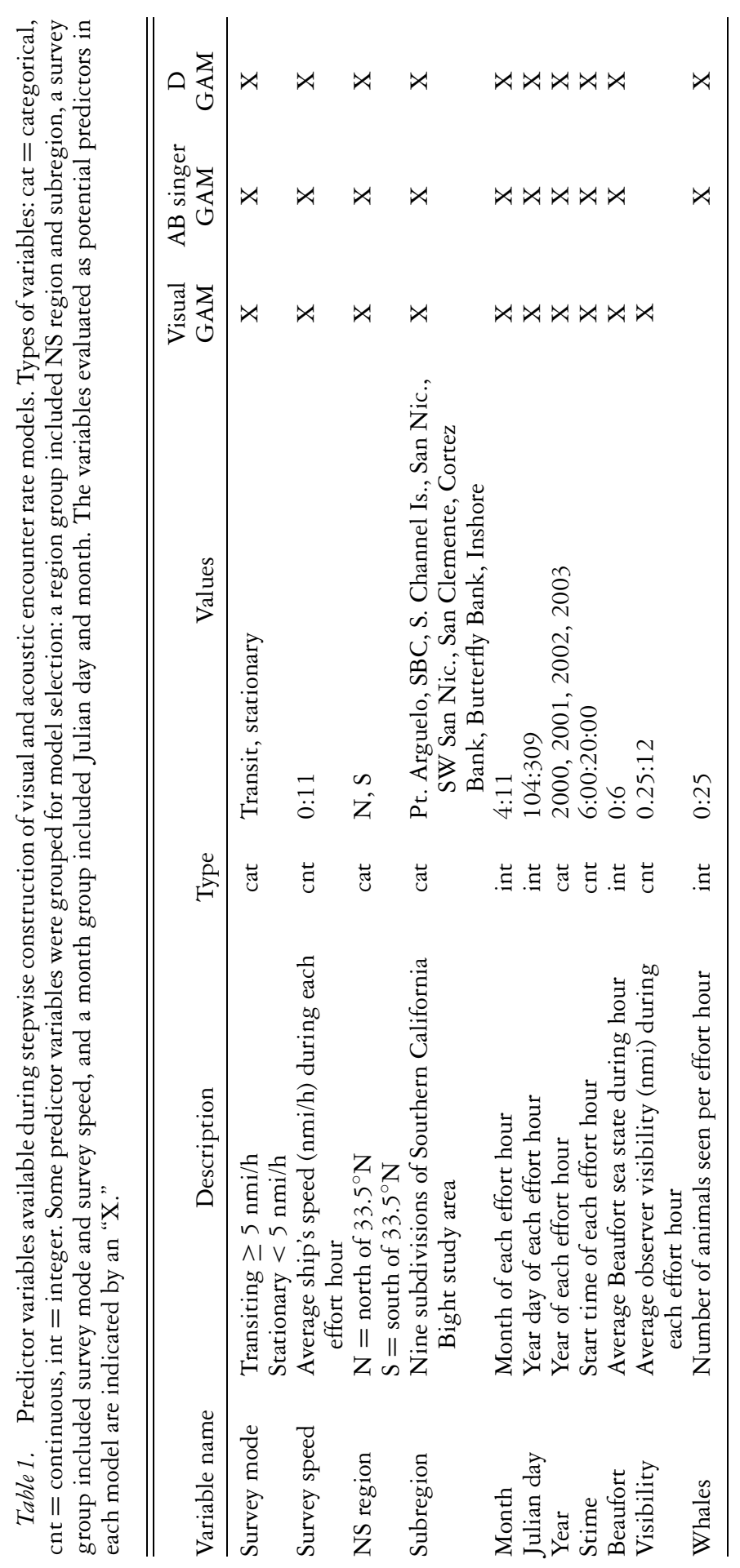


be quantitatively interpreted. When the original stepwise selection procedure chose nonparametric fits of predictor variables, a special form of ANOVA, or analysis of deviance for GAM objects was implemented within S-Plus. The deviance is analogous to the residual sum of squares for generalized likelihood models and therefore may be used to assess goodness of fit and to compare models. The contribution of the nonparametric portion of each predictor was tested $v s$. a linear parameterization. A nonsignificant result for a particular predictor variable indicated that the variable could be parametric without significant loss of explanatory power. The scope of nonparametric predictors with insignificant $P(F)$ values $(<0.05)$ was reparameterized using polynomial or exponential terms and the model selection process run again. Changes in overall model fit using the reparameterized predictors were tested using an analysis of deviance between models. Nonsignificant results indicated that the fit was not altered by the reparameterization.

AIC has a tendency to over-fit models (Kass and Raferty 1995); therefore, the contribution of each predictor in the model was tested using a final analysis of deviance among model predictors. The significance of each predictor was examined by adding predictors one at a time to the model and sequentially testing for changes in model fit through the calculation of a likelihood score. When a predictor did not significantly contribute to the model fit, the least significant predictor was eliminated and the remainder of the predictors tested again. This iterative process continued until all remaining predictors were significant contributors to the model. Final encounter rate models were inverted to the scale of the response using the logarithmic relationship to allow for comparison among models.

\section{RESULTS}

There were a total of $414 \mathrm{~h}$ of concurrent visual and acoustic effort, within which there were $157 \mathrm{~h}$ with visual encounters, $185 \mathrm{~h}$ with acoustic encounters of whales producing $\mathrm{AB}$ song, and $106 \mathrm{~h}$ with acoustic encounters of whales producing $\mathrm{D}$ calls. Several hours have both visual and acoustic detections, usually representing detections of different groups. With the exception of surveys occurring in April, there were visual and acoustic detections of blue whales in all surveyed months and regions. Encounter rate is standardized as whales detected per hour for each encounter type. The spatial and temporal distributions of effort and hourly counts of visual and acoustic detections are shown for June-July (Fig. 2), August (Fig. 3), and OctoberNovember (Fig. 4).

\section{Visual Encounter Rate Model}

The best-fit visual encounter rate model includes temporal and spatial variables, with an overall average of 2.06 whales seen per hour $(\mathrm{CV}=0.10)$. The significant explanatory variables were subregion, Julian day, hourly start time, and year (Table 2, Fig. 5). Julian day and start time variables were best described using nonparametric smoothing splines. Visual encounters were highest from June to August and then decreased through November. Blue whales were seen more often in the Santa Barbara Channel (SBC), south of the Channel Islands, and in the San Nicolas regions relative to the rest of the study area. Low visual encounter rates in 2003 were due, in part, to reduced effort in the regions of highest sighting probability in that year. 


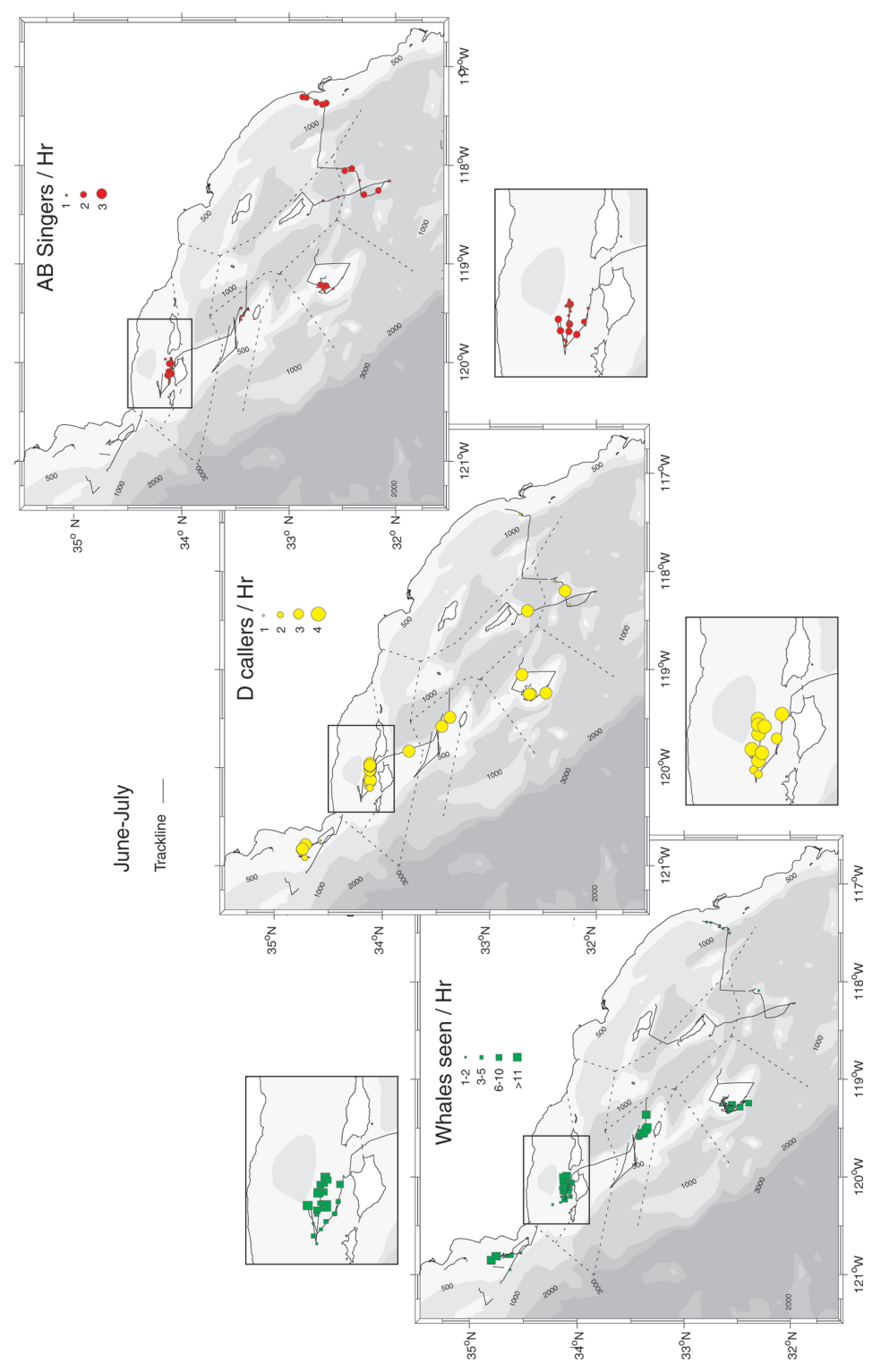

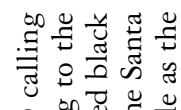

ค.

ही

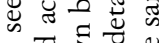

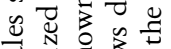

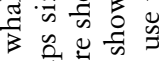

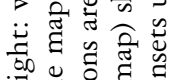

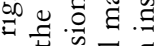

ㄴ.

400

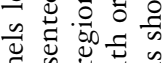

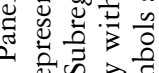

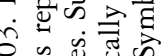

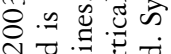

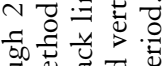

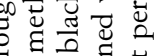

可 合

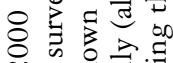

讨

$\circ \mathscr{E}^{\circ}$

至古芯芯

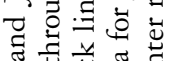

政范

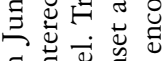

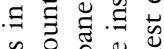

造造造

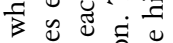

墕.

근

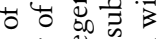

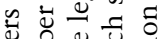

可

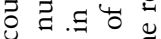

过

氙和

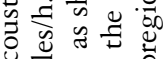

过造泀

ส

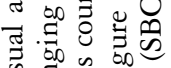

$>$ 品造江

乎专

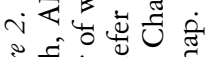

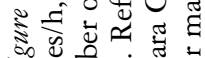

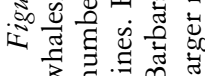




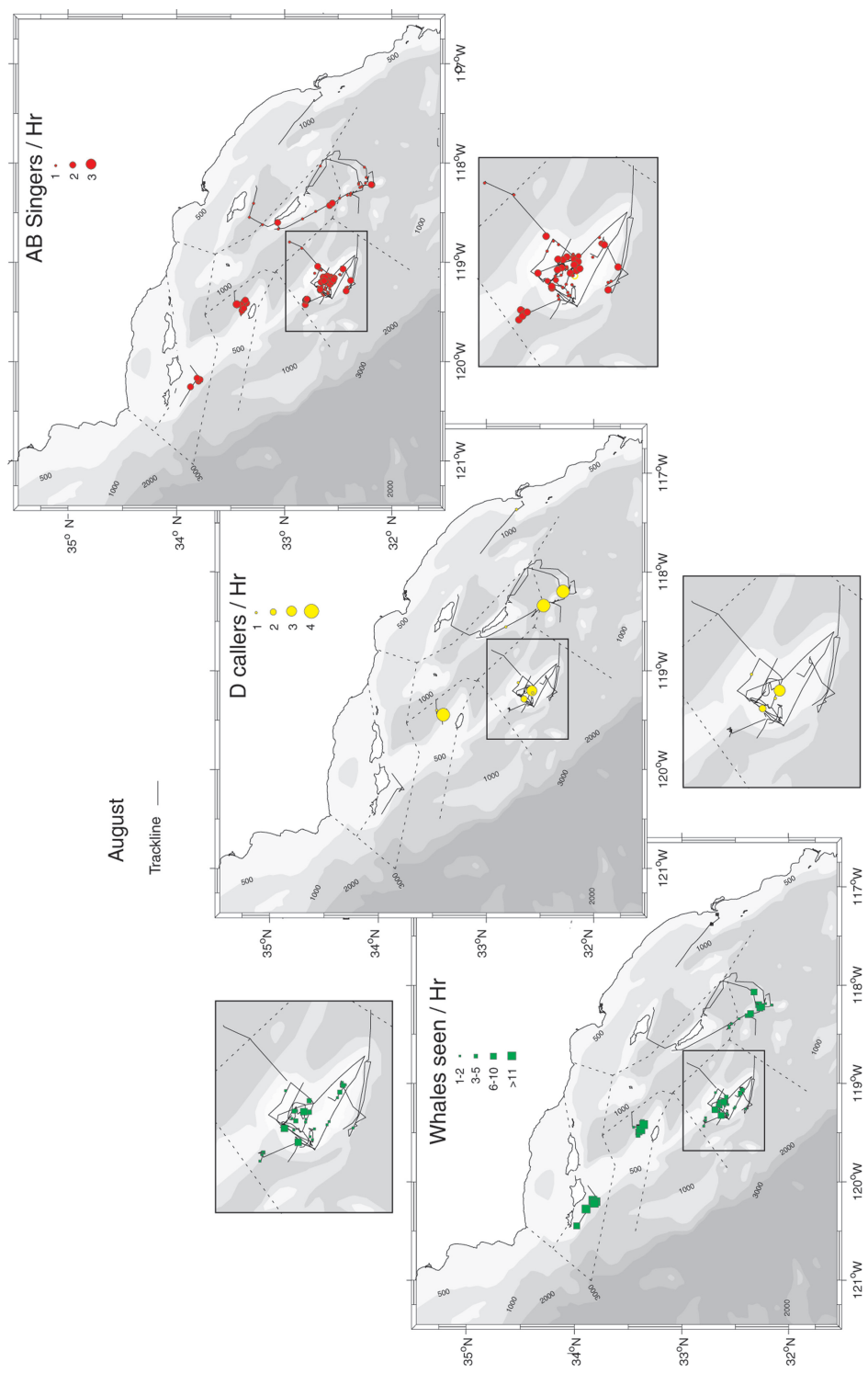

ही 过

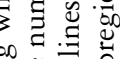

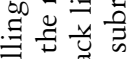
전 a 000

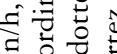
顿合

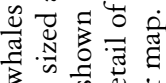
نे के

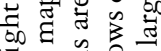

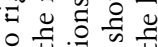

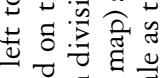
离

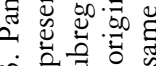
$\dot{0}$ 은 员为 두의

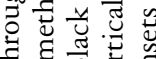
5 焉 品 ญे

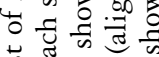

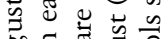
50 50

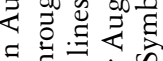

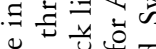

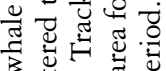
过

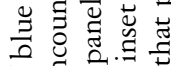

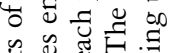
造过

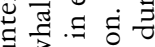

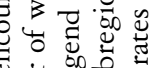
远造券 氜

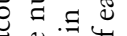

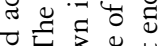

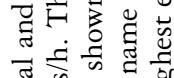
बే $>\frac{\pi}{3} \bar{d} \frac{\vec{u}}{0}$ $\dot{n}$ 我号 \%

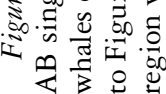




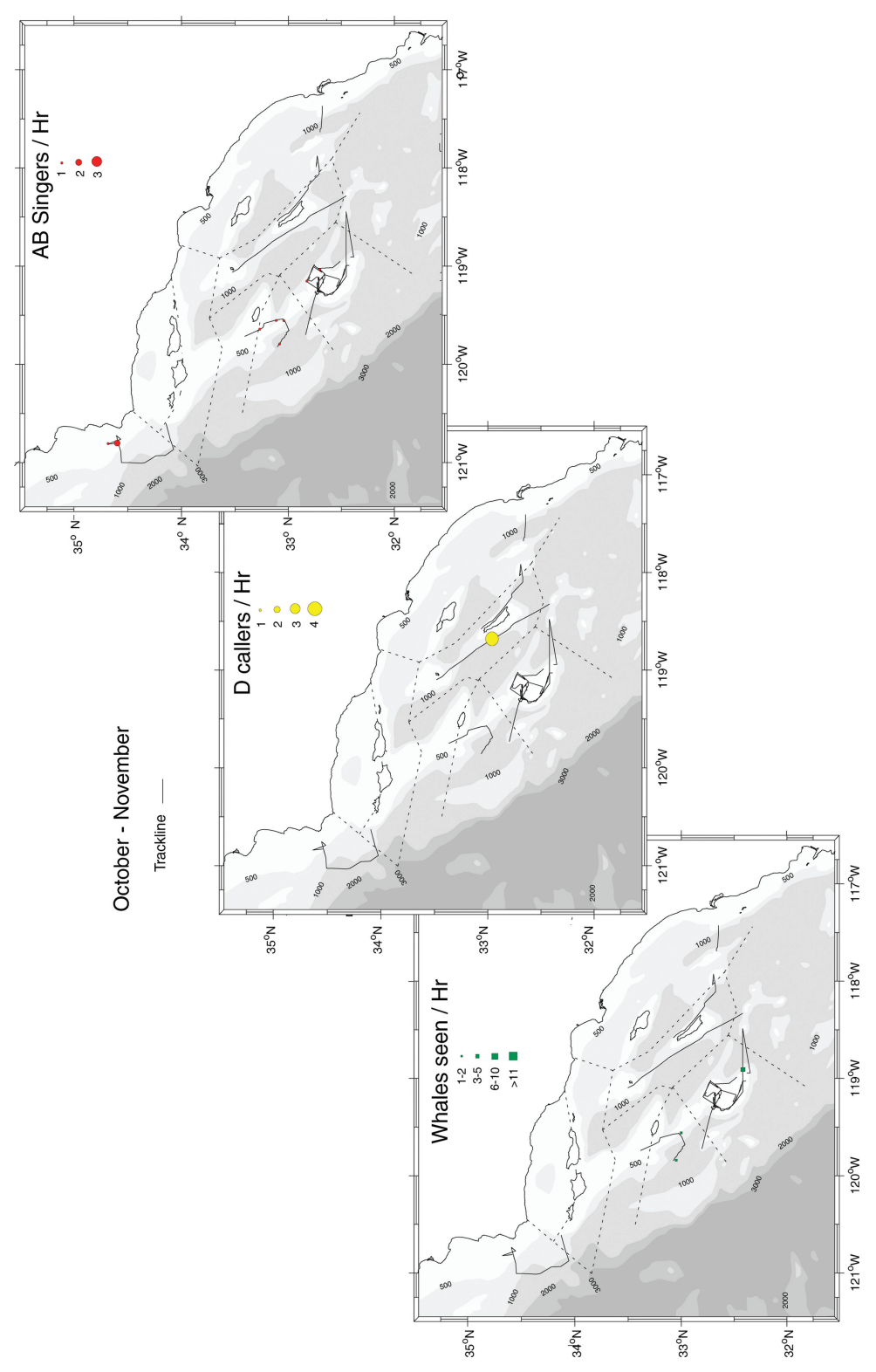

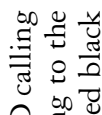

$\circ .00$

Eं

氙完

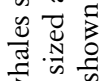

范范

$\overbrace{0,0}$

돈

$\stackrel{+}{=}:$

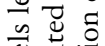

बै

听艺

ชै

의

도음

矛苛

웜

号寻

낭 든

过

है 동

है

$Z_{1}$

嵌

ठั

. ర్ Љ

워 च्ञ

శ్표

B.

当

पै

s

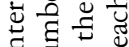

吾寻出

छี

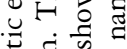

के

ชै

च

त.

马ु 0000

$>$ के

.

产范

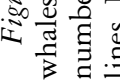


Visual encounter rate increased moderately with time of day, likely an artifact of the tendency to switch to stationary effort when several whales were sighted.

\section{Acoustic Encounter Rate Model for Whales Producing AB Song}

Acoustic encounter rates of whales producing $\mathrm{AB}$ song also varied temporally and spatially, with an average encounter rate of 0.65 animals per hour $(\mathrm{CV}=0.06)$. The best-fit encounter rate model for singing blue whales included Julian day, survey mode, and subregion variables (Table 2, Fig. 6). Singing blue whales were more common in the early fall with fewer detections in June and November. The probability of detecting a singing blue whale was modestly higher in stationary mode. Geographic variability was evident with the highest encounter rates ( $>1$ whale heard per hour) occurring in the San Nicolas region, followed by the Butterfly Bank, Cortez Bank, and Inshore regions.

\section{Acoustic Encounter Rate Model for Whales Producing D Calls}

Variability in the average acoustic encounter rate for whales producing D calls $(0.42$ animals per hour, $\mathrm{CV}=0.09$ ) was best explained by a model that included Julian day and the number of animals seen per hour (Table 2, Fig. 7). Acoustic encounters of $\mathrm{D}$ calling whales were the highest in July and August, with sharply decreasing

Table 2. Final parameters for visual and acoustic encounter rate models. The contribution of each variable to model fit was evaluated using Akaike's information criterion (AIC) and the change in deviance. The change in AIC ( $\triangle$ AIC) represents the increase in model fit $v s$. the addition of degrees of freedom ( $\Delta \mathrm{df})$ at each step of model selection. Lower values of AIC indicate increased fit with the best-fit model assigned an AIC value of 0 . The notation poly() and $s()$ represent a polynomial or spline fit, respectively, of the predictor variable during model selection. The number of degrees of freedom for these fits is shown in the parentheses following the variable name. The number of degrees of freedom, deviance, and AIC of the null model are presented to indicate model selection starting values.

\begin{tabular}{|c|c|c|c|c|c|}
\hline Model & $\Delta \mathrm{df}$ & Deviance & $\Delta \mathrm{AIC}$ & $F$ value & Probability $(F)$ \\
\hline \multicolumn{6}{|l|}{ Sighting model } \\
\hline Null model & 414 & 2364.6 & 1007.6 & & \\
\hline Subregion & 8 & 1494.5 & 216.5 & 33.2 & $<0.0001$ \\
\hline$s($ time of day, 2) & 3.8 & 1265.8 & 167.7 & 23.0 & $<0.0001$ \\
\hline s(Julian day, 3) & 1 & 1211.6 & 92.7 & 16.6 & 0.0002 \\
\hline Year & 1 & 1190.3 & 0 & 6.5 & 0.0351 \\
\hline \multicolumn{6}{|l|}{$\mathrm{AB}$ singer model } \\
\hline Null model & 414 & 468.2 & 137.9 & & \\
\hline poly(Julian day, 2) & 2 & 402.0 & 54.9 & 37.9 & $<0.0001$ \\
\hline Survey mode & 1 & 358.7 & 13.6 & 49.6 & $<0.0001$ \\
\hline Subregion & 8 & 308.4 & 0 & 7.2 & $<0.0001$ \\
\hline \multicolumn{6}{|l|}{ D caller model } \\
\hline Null model & 414 & 501.3 & 165.8 & & \\
\hline Whales $^{0.5}$ & 1 & 381.6 & 49.1 & 86.9 & $<0.0001$ \\
\hline poly(Julian day, 2) & 2 & 326.5 & 0 & 20.0 & $<0.0001$ \\
\hline
\end{tabular}



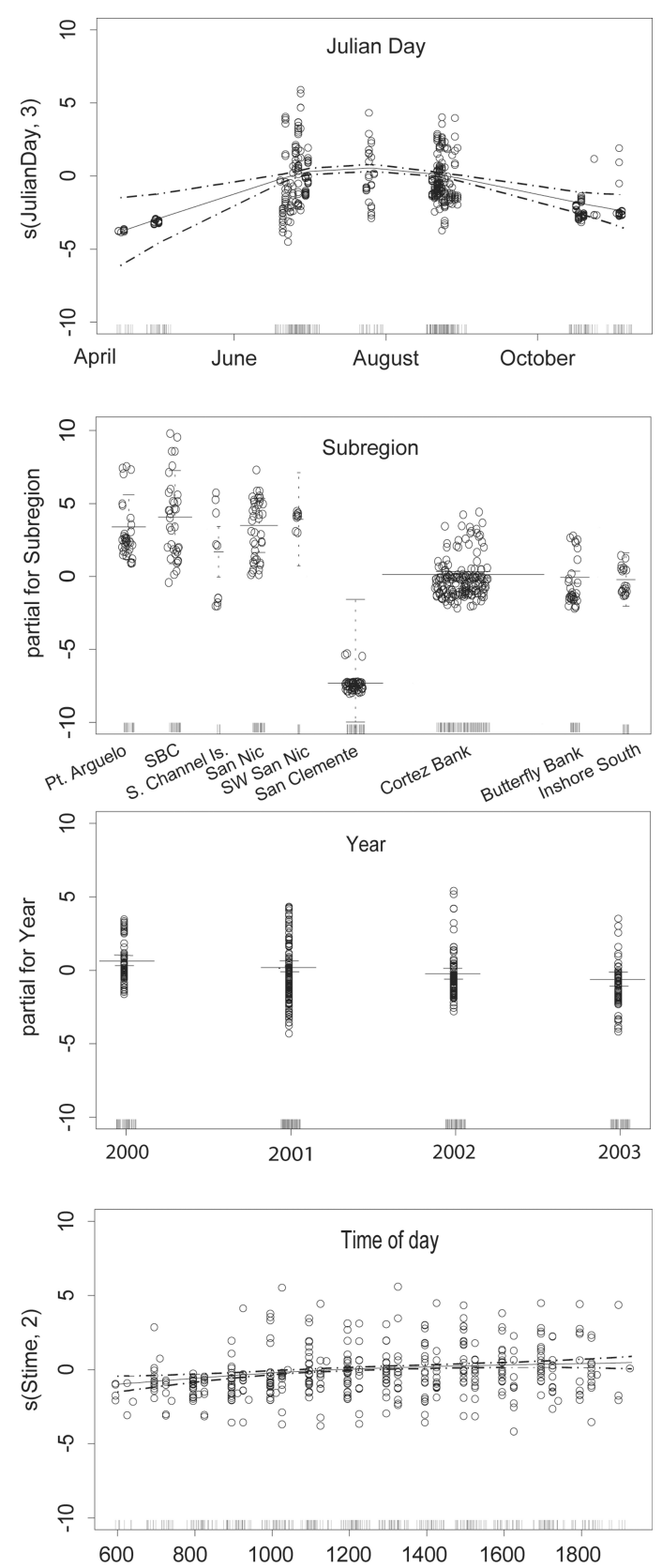

Figure 5. The mean-adjusted partial fit of each predictor variable for the best visual encounter rate model. Higher values on the $y$-axis indicate more whale detections. The plots show the average of the partial fit (solid line), the standard error of the fit (dash-dot line), and the partial residuals (o). The vertical lines along the $x$-axis indicate the number of observations at each value of the predictor variable. 

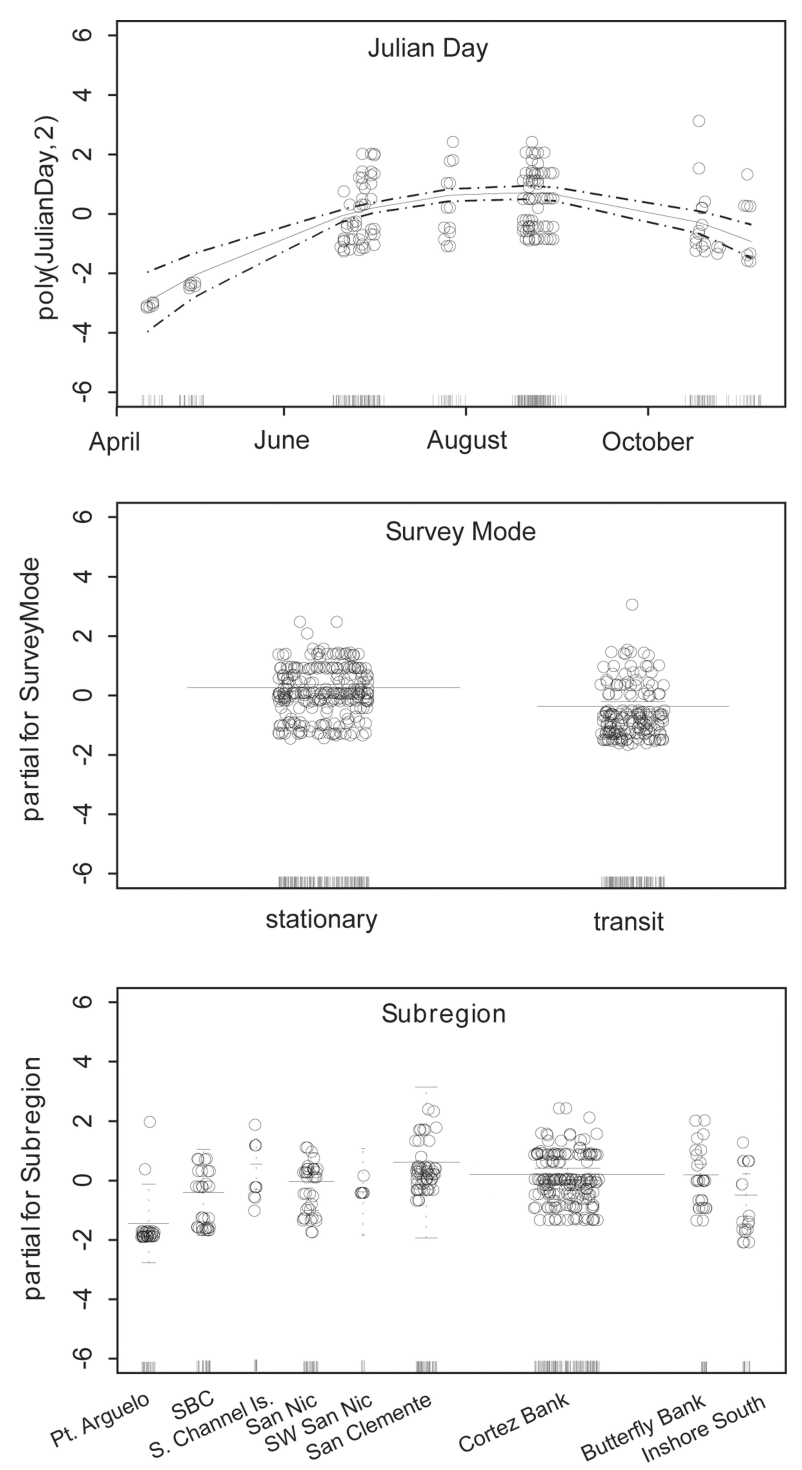

Figure 6. The mean-adjusted partial fit of each predictor variable for the best acoustic encounter rate model for whales heard producing $A B$ song. Higher values on the $y$-axis indicate more whale detections. The plots show the average of the partial fit (solid line), the standard error of the fit (dash-dot line), and the partial residuals (o). The vertical lines along the $x$-axis indicate the number of observations at each value of the predictor variable. The survey was considered stationary when the ship traveled less than $5 \mathrm{nmi} / \mathrm{h}$.

numbers into the fall. The predicted relationship of the number of $\mathrm{D}$ callers heard and the number of blue whales seen is a good fit to the original data (Fig. 8). The encounter rate of $\mathrm{D}$ calling whales was likely biased downward due to the potential assignment of calls produced by closely spaced whales to a single caller. 

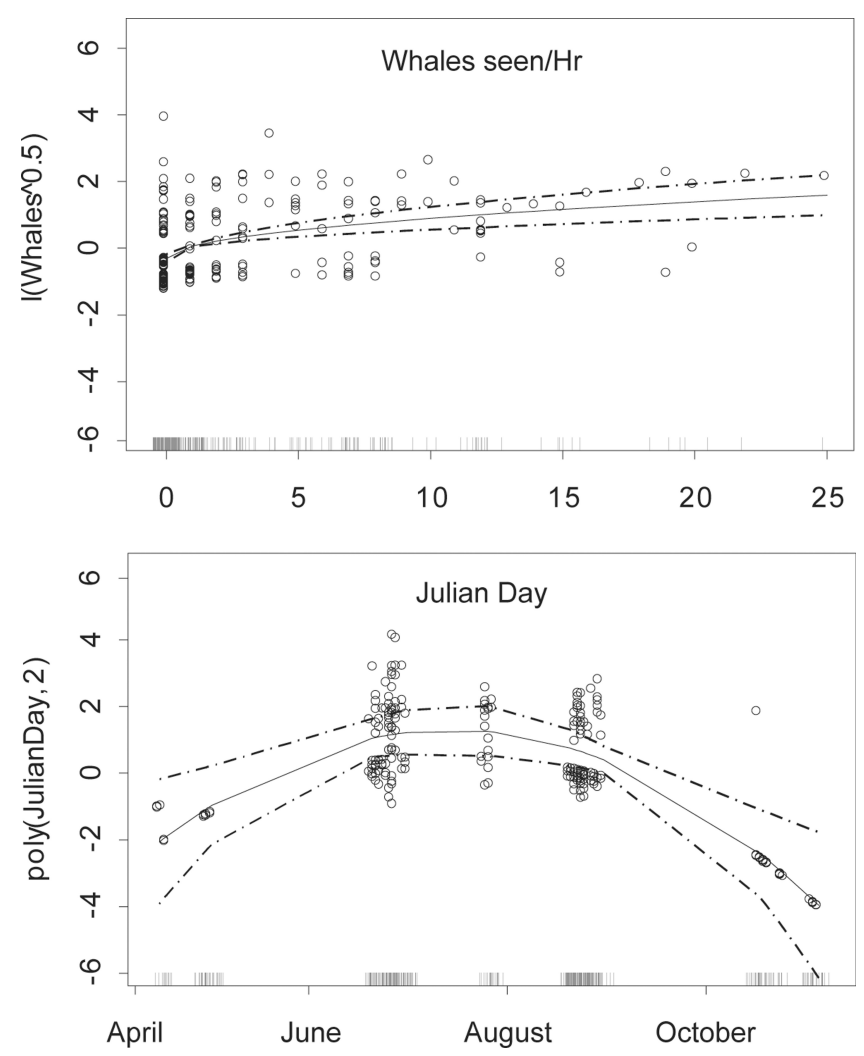

Figure 7. The mean-adjusted partial fit of each predictor variable for the best acoustic encounter rate model for whales heard producing D calls. Higher values on the $y$-axis indicate more whale detections. The plots show the average of the partial fit (solid line), the standard error of the fit (dash-dot line), and the partial residuals (o). The vertical lines along the $x$-axis indicate the number of observations at each value of the predictor variable.

\section{Model Comparisons}

Subregion was included as a significant contributor in two encounter rate models: visual encounter rate and acoustic encounter rate of whales producing $\mathrm{AB}$ song. The difference between visual and acoustic encounter rates in each subregion was tested for significance using a bootstrap test for the equality of means (Efron and Tibshirani 1998), a bootstrap analogue to the Student's $t$-test. The achieved significance level (ASL) of each test, equivalent to the $P$ value (Efron and Tibshirani 1998), is shown for each subregion in Figure 9. The probability of visually encountering a blue whale was significantly greater than the probability of acoustically encountering a singing whale in the SBC, south of the Channel Islands, and San Nicolas regions of the study area. Visual and acoustic encounter rates were similar in the central and southeastern regions of the Southern California Bight.

Julian day was a significant predictor in all three encounter rate models. The timing of the predicted seasonal distributions of visual encounters, acoustic encounters of whales producing $\mathrm{AB}$ song, and acoustic encounters of whales producing $\mathrm{D}$ calls 


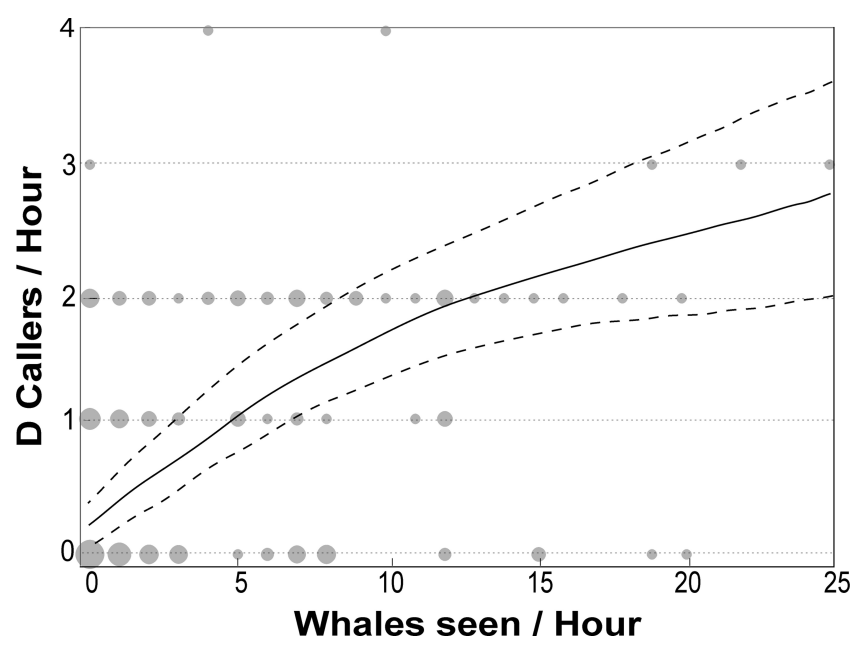

Figure 8. The acoustic encounter rate of whales producing D calls was predicted by the number of blue whales seen per hour. Gray circles show original data $(n=414)$, with the size of the circle scaled to represent the number of observations at each value of ( $\mathrm{D}$ callers/h, whales seen/h). As suggested by the GAM, the predicted fit is significantly related to the original data $\left(r^{2}=0.745, F=1069.1, P<0.001\right)$. The decreasing slope of this relationship is likely due to a negative bias in the observed number of $\mathrm{D}$ calling whales per hour at high densities because of the difficulty in counting all animals producing $\mathrm{D}$ calls when animals occurred on similar bearings.

were compared using the Kruskal-Wallis test for differences in location (Sokal and Rohlf 1981). The test revealed significant differences in seasonal timing among the encounter types $\left(\chi^{2}=147.5, P<0.001\right)$. Further pairwise comparisons using a multiple comparisons test indicated that the seasonal timing of acoustic encounters of whales producing $\mathrm{AB}$ song was significantly later than both the seasonal timing of visual encounters and the acoustic encounters of whales producing $\mathrm{D}$ calls. The seasonal timing of visual encounters and acoustic encounters of D callers did not differ significantly.

\section{DISCUSSION}

\section{Seasonality}

Blue whale encounter rates are expected to vary seasonally. Blue whales are migratory and spend only a portion of the year in the Southern California Bight before returning to lower latitude breeding grounds (Calambokidis et al. 1990, Mate et al. 1999). The significant difference in the seasonal distribution of the two acoustic encounter rates and the difference between acoustic encounters of singing whales and visual encounters suggest seasonal variation in the ability of each method to detect blue whales. This finding is similar to the seasonal shift between $\mathrm{B}$ and $\mathrm{D}$ call occurrence observed from autonomous acoustic records in this region (Oleson et al., in press). Bias may arise in the ability to detect blue whales visually or acoustically due to seasonal changes in whale behavior. Such variation in encounter rates may suggest 


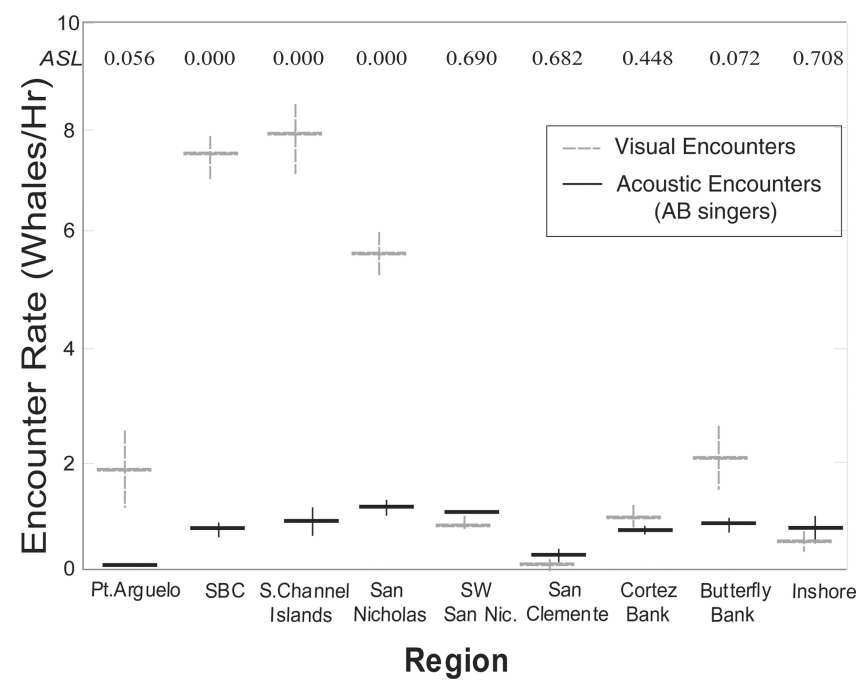

Figure 9. Encounter rate of blue whales seen and blue whales heard producing $\mathrm{AB}$ song in each subregion. Subregion was chosen as a significant predictor of encounter rate for both models. The mean and bootstrap standard errors (SE), based on 200 bootstrap samples of the predicted values, are given for each encounter type in each subregion. The achieved significance level (ASL) for the comparison of the number of whales seen $v$ s. heard producing $\mathrm{AB}$ song in each subregion is shown along the top axis for each region.

that a single detection method may not be adequate to account for the abundance of the local blue whale population during the feeding season.

The seasonal differences in blue whale call types may be related to foraging and reproductive behaviors. Each blue whale call type (AB song calls, $\mathrm{AB}$ single calls, and $\mathrm{D}$ calls) is associated with a different behavioral and environmental context (Oleson et al. 2007). The two call types examined here, $A B$ song and $\mathrm{D}$ calls, are the most distinctive in their behavioral context. Feeding whales of both sexes produce $\mathrm{D}$ calls, whereas $\mathrm{AB}$ song calls are produced by male blue whales, commonly when traveling (Thode et al. 2000, Watkins et al. 2000, McDonald et al. 2001, Oleson et al. 2007). Our models suggest that D calls are more common early in the summer (Fig. 10) when blue whales migrate into the Southern California Bight to forage. In the fall, as the breeding season approaches, the detection of $\mathrm{AB}$ song increases. Although $\mathrm{AB}$ calls can be heard year-round in some regions (Stafford et al. 2001), the fall increase in the occurrence of these calls off southern California (Burtenshaw et al. 2004; Oleson et al., in press, this study) is likely related to the approaching mating season.

Seasonal differences in visual and acoustic detection rates may have implications for the interpretation of blue whale abundance surveys. Visual encounters and acoustic encounters of whales producing $\mathrm{D}$ calls have similar seasonality, with a peak in the summer and declining encounters late into the fall. These results are similar to other visual surveys for blue whales in the Southern California Bight (Forney and Barlow 1998, Larkman and Veit 1998, Carretta et al. 2000). However, the fall peak in AB song is generally not represented in seasonal abundance estimates. There are several possible explanations for the increase in the number of whales heard producing $\mathrm{AB}$ song relative to the number of whales seen. First, the relative increase would be observed if 


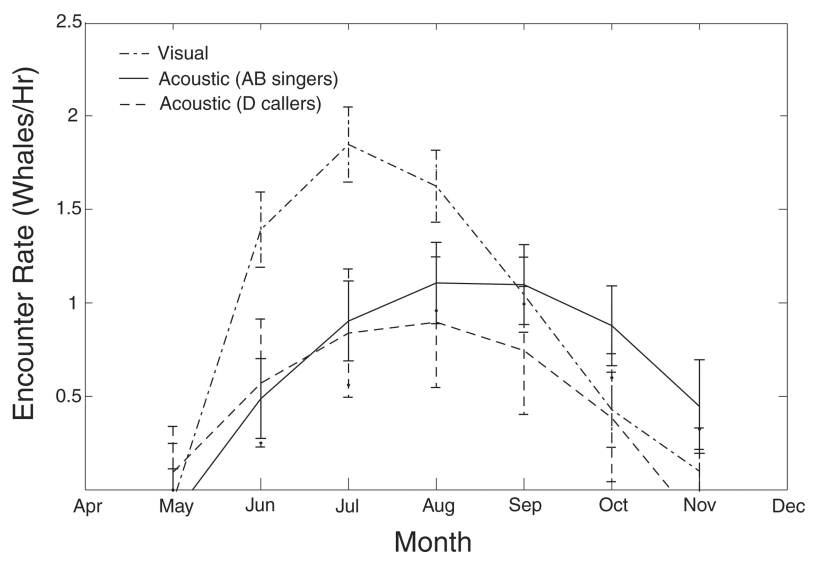

Figure 10. Seasonal distribution of visual and acoustic encounter rate (whales/h) predicted from the best-fit models and controlling for other variables. Julian day was chosen as a significant predictor in all encounter rate models. The mean and bootstrap standard errors, based on 200 bootstrap samples of the predicted values, are shown for each month. Month was assigned with the first as the midpoint; such that July includes all detections from 15 June to 15 July. The average seasonality for each encounter type, shown by the line indicated in the legend, follows the shape predicted in each model.

animals that were not singing earlier in the season started to sing in the fall. As whale density declines in southern California during the southbound migration, the rate of visual detection would also decline, whereas acoustic detection would increase as the proportion of whales singing increased. This relative increase in acoustic detection would be exaggerated if singing behavior inhibited visual detection. For example, shorter surface intervals are often observed from traveling whales (Acevedo-Gutierrez et al. 2002), effectively reducing the probability of visual detection compared to that expected based on the density of whales. Second, the relative increase in AB singing whales could be observed if the amount of time spent singing by individual males increased in the fall. The increased calling rate would increase the likelihood of acoustic detection as the whale moves by the monitoring location. The rate of missed visual detection would remain constant whereas the probability of acoustic detection would increase. Finally, a bimodal or extended peak in abundance might occur if singing whales migrate later in the season than other segments of the population. A delayed migration should be evident through visual surveys alone, as has been observed for humpback and gray (Eschrichtius robustus) whales (Rice and Wolman 1971, Dawbin 1997) unless singing whales are more difficult to detect visually. Further study on the probability of visually detecting singing whales and the singing behavior of individual males is needed before we can determine which process is governing the observed disparity between visual and acoustic encounter rates.

\section{Geographic Variability}

The significant geographic variability in visual encounters and acoustic encounters of $\mathrm{AB}$ singing blue whales (Fig. 9) is likely related to the dynamic oceanography in the Southern California Bight. Large aggregations of blue whales are consistently 
observed in the northern portion of the study area, including the SBC, south of the Channel Islands, and San Nicolas subregions, where visual detections rates were significantly higher than acoustic detections of singing whales. The distribution of blue whales within this region is determined in part by their attraction to areas of predictably high prey density (Croll et al. 1998), such as the northern Channel Islands. High prey density is sustained by levels of high primary productivity downstream from coastal upwelling centers. Increased productivity may also explain the elevated visual detection rates in the Cortez Bank and Butterfly Bank subregions, as the dynamic bathymetry in those regions may concentrate high densities of euphausiids.

In addition to relatively high visual encounter rates, acoustic encounter rates of singing whales were also high at the Cortez Bank and Butterfly Bank subregions. With few exceptions, hours containing both visual and acoustic detections represent detections of different groups, with the animals that are seen independent of those that are heard. The similarity in the visual and acoustic encounter rates in the Cortez Bank and Butterfly Bank subregions suggests that these areas may represent portions of the Bight important to both feeding and traveling whales. Blue whales move frequently among areas of high prey density during the feeding season (Mate et al. 1999), increasing the likelihood of encountering traveling whales near and between areas with concentrations of feeding whales. In these regions, concurrent visual and acoustic monitoring may be important, as the probability of visually detecting singing whales appears to be low.

Maps of visual and acoustic detections of blue whales during this survey (Fig. 2-4) indicate that some interaction between spatial and temporal variables may exist as whales change their distribution in the Bight over the course of the feeding season. We did not include interaction terms in our models as this seemed inappropriate given the relatively small sample size within some regions and seasons. However, future systematic studies of blue whale distribution and abundance both within the Bight and over their broader foraging range should be investigated as these patterns may indicate consistent movement among regions throughout the feeding season, potentially defining seasonal habitat preferences.

\section{Calibration of Acoustic Surveys}

Acoustic survey methods offer the ability to detect vocal cetaceans when they are not available to visual observers due to darkness, poor weather, or availability of animals at the sea surface. However, the detection radius is nearly always different between acoustic and visual methods. Acoustic detection range is dependant on physical and biological features, such as water temperature, bathymetry, ambient noise level, and the directionality and amplitude of produced calls. Visual detection range is dependant on sea state, weather, and how visible an animal is when at the surface. Acoustic detection distances can be tens of kilometers or greater for baleen whales (Clark and Fristrup 1997, McDonald 2004), whereas visual survey detection distances are generally on the order of a few kilometers. On two occasions when a blue whale was initially encountered acoustically, the whale was eventually found nearly $10 \mathrm{~km}$ from the initial acoustic detection. This distance is outside the typical visual detection range.

Calculation of acoustic detection distance requires knowledge of either the source amplitude of the call and the acoustic transmission properties of the water column or enough sensors to locate the calling whale. Neither of these conditions was met 
during our survey. The bathymetry of the Southern California Bight is complex, and the temperate waters are generally downward refracting (Urick 1983), likely limiting detection distances from near-surface hydrophones (within or above the thermocline) to tens of kilometers or less. Acoustic detection distance is also likely to vary among survey regions and seasons. We have not attempted to account for potential changes in acoustic detection distance and this may have introduced variability, both regionally and seasonally, into our models.

Our blue whale encounter rate models (Table 2) indicate that each encounter type is predicted by a unique combination of spatial and temporal factors. The seasonal dependence in all three encounter types and the spatial variability in acoustic encounters of singing whales and visual encounters result in a complicated relationship between visual and acoustic encounter rates. Our encounter rate models indicate that the proportion of animals heard producing $A B$ song increases during the feeding season and that the number of animals producing song is not well predicted by the number of animals seen. This suggests that the commonly reported and widely studied $\mathrm{AB}$ call type is, in general, not a good indicator of overall whale density. In contrast, the encounter rate of whales producing $\mathrm{D}$ calls tracked visual encounters seasonally and geographically, with acoustic encounter rates of $\mathrm{D}$ calling whales ultimately predicted by the number of animals seen. Unlike AB song, D calls are produced by both male and female blue whales (Oleson et al. 2007), such that monitoring of this call type potentially results in sampling a larger segment of the population. In addition, it is likely that similar behaviors, such as feeding, and environmental features, such as high prey biomass, govern the distribution of whales that are seen and whales that are heard D calling.

The presence of whales producing $\mathrm{D}$ calls may therefore be a better indicator of blue whale distribution and relative abundance than whales producing $A B$ song. However, the variability in sweep rate and frequency content of $\mathrm{D}$ calls produced by a single animal complicate the unique identification of nearby whales using frequency and amplitude characters. By counting only unique bearings rather than individual calls, we have eliminated the possibility of counting two or more calling whales on a similar bearing. The relationship between the number of whales producing $\mathrm{D}$ calls and visual sightings does appear to show an upper limit to the number of D callers that may be identified. More research is required on the potential for a density-dependant relationship between $\mathrm{D}$ calling and the number of animals present; however, it does appear that counting D calls, as opposed to counting the number of whales producing $\mathrm{D}$ calls, may be a more robust means of estimating the number of animals in a region. This relationship may be determined through directed studies of whales producing $\mathrm{D}$ calls using visual methods, acoustic recording tags, or acoustic tracking arrays capable of detecting small differences in animal location.

The distinct spatial and temporal patterns of visual detection of whales $v$ s. acoustic detection of singers indicate that neither visual nor acoustic surveys may survey blue whale presence without increased variability due to behavior or environmental features (Fig. 2-4). The utility of acoustics for detecting vocal cetaceans has been proven many times (Mellinger and Barlow 2003). However, it remains an open question whether a method will be developed to use counts of whales producing $\mathrm{AB}$ song to estimate absolute abundance. Blue whales are commonly heard on ship surveys during which they are rarely seen (Clark and Fristrup 1997; Rankin et al. 2005; Sirović et al., 2006). Minimally, these acoustic detections may yield estimates of the number of animals missed by visual surveys alone, although the nearly complete independence of those animals that are seen and those that are heard (Clark and 
Fristrup 1997; Rankin et al. 2005; Širović et al., 2006 this study) suggest that acoustic surveys for $\mathrm{AB}$ song alone will not be effective for estimating absolute abundance.

The results of our survey are somewhat in contrast with those of previous shipboard surveys for blue whales that have often found higher acoustic than visual encounter rates (e. g., Clark and Fristrup 1997; Rankin et al. 2005; Širović et al., 2006). However, it is difficult to compare our results with those of previous surveys as each has used different analysis methods. By accounting for temporal, geographic, and survey variables we have described the variation in encounter rate, whereas previous studies have generally not accounted for this variation. Although our models indicate that the average visual encounter rate is higher than acoustic encounter rates, acoustic encounters of singing whales did exceed visual encounters from September through November (Fig. 10), the same period described by Clark and Fristrup (1997). Their surveys also focused on regions where singing whales were most commonly heard, potentially influencing visual $v s$. acoustic encounter rate estimates.

\section{Limitations of the Survey Design}

The inclusion of the "year" and "time-of-day" predictors in the visual encounter rate model are likely not indicative of a real decrease in the use of the Southern California Bight from 2000 to 2003, or of an increased ability to see blue whales later in the day. The shipboard survey described here was not systematic. Although the algorithms of the GAM are designed to remove the dependence of the response variable on each of the predictors in turn, the dependencies in highly confounded data may be difficult to separate fully. For example, the largest aggregations of blue whales were found in the SBC, south of the Channel Islands (S. Channel Is.), and San Nicolas Island (San Nic.) subregions. However, in 2003, no regions north of San Nicolas were surveyed due to the necessity to keep the ship in the southerly regions to aid in other studies. Although interannual variability in habitat use could account for the decrease in encounter rates from 2000 to 2003, the geographic distribution of effort over this period is the most likely cause of the apparent decline. Likewise, the decline is likely not due to a real change in blue whale abundance, as the blue whale population is thought to be stable (Calambokidis and Barlow 2004). Similarly, an increase in visual detection rates throughout the day is likely related to the common transition to a stationary survey mode later in the day, not to a change in whale behavior. It is important to note that a systematic survey would not likely show encounter rate to depend on time of day. Although our results may vary significantly from systematic surveys of blue whale abundance and distribution in the Bight, these results do provide some insight into the utility of acoustic surveys for the detection of blue whales during ship-based surveys and for evaluating autonomous acoustic records.

\section{Conclusions}

Comparison of visual and acoustic detection rates is one method for validating the use of acoustic surveys, either mobile or autonomous, for estimating cetacean abundance. Our results show that visual and acoustic detection rates differ seasonally and geographically within the Southern California Bight. These differences suggest that a single detection mode may be insufficient to detect blue whales in all seasons and regions. Behavior and calling are linked, such that production of certain call 
types may be correlated with specific behaviors (such as long dive duration) that make whales difficult to detect visually. Conversely, these behaviors may not be tied to whale density such that acoustic detection alone may not provide a reliable estimate of abundance, particularly in regions with large aggregations of blue whales. Further study on the acoustic behavior of blue whales should help us to better understand the patterns observed here and make quantitative connections between visual and acoustic encounter rates.

\section{ACKNOWLEDGMENTS}

We thank the visual observers for their efforts in spotting and keeping track of blue whales during this survey; Kristin Rasmussen, Todd Chandler, and Jessica Burtenshaw provided consistency in the visual surveys and were aided by many other CRC and SIO visual observers. Annie Douglas and Lisa Schlender compiled and managed the visual survey data. Allan Sauter, Melissa Soldevilla, Sean Wiggins, and Mark McDonald provided assistance with acoustic hardware and analysis at sea. We also thank the captain and crew of the R/V Sproul for their hard work and patience during these surveys. Among the many others who helped during the course of our surveys and analysis, we thank Bill Gaines at SIO who obtained sonobuoys from the U. S. Navy for this project, Dave Mellinger for providing a link between ISHMAEL and the Greeneridge Sciences, Inc. sonobuoy de-multiplexing software, and Megan Ferguson for her valuable advice and assistance in building the GAMs. This work was funded by the U. S. Navy's Strategic Environmental Research and Development Program (SERDP) under the program management of Robert Holst, the Chief of Naval Operations, division N45, with support from Frank Stone, Linda Petitpas, and Ernie Young, and the Office of Naval Research, with program management from Jeff Simmen, Ellen Livingston, and Bob Gisiner. Sonobuoys were deployed within the Channel Islands National Marine Sanctuary under research permits CINMS-07-00, CINMS-2001-001, and CINMS-2002-003. This work was part of the doctoral dissertation of E.M. O. and was carried out under the watchful eyes of her doctoral committee: Sue Moore, Paul Dayton, Dave Checkley, Jim Moore, JAH, and JB. Previous versions of this manuscript were improved by the thoughtful critique of Phil Clapham and three anonymous reviewers.

\section{LITERATURE CITED}

Acevedo-Gutierrez, A., D. A. Croll and B. R. Tershy. 2002. High feeding costs limit dive time in the largest whales. Journal of Experimental Biology 205:1747-1753.

AKAIKE, H. 1973. Information theory and an extension of the maximum likelihood principle. Pages 267-281 in B. N. PETRAN AND F. CSAAKI, eds. Second International Symposium on Information Theory. Akadeemiai Kiadi, Budapest, Hungary.

AKAmatsu, T., D. WANG, K. WANG AND Z. WeI. 2001. Comparison between visual and passive acoustic detection of finless porpoises in the Yangtze River. Journal of the Acoustical Society of America 109:1723-1727.

BARLOW, J., AND B. L. TAYLOR. 2005. Estimates of sperm whale abundance in the northeastern temperate Pacific from a combined acoustic and visual survey. Marine Mammal Science 21:429-445.

Buckland, S. T., D. R. Anderson, K. P. Burnham, J. L. LaAke, D. L. Borchers and L. THOMAS. 2001. Introduction to distance sampling, estimating abundance of biological populations. Oxford University Press, New York, NY.

Burtenshaw, J. C., E. M. Oleson, M. A. McDonald, J. A. Hildebrand, R. K. ANDrew, B. M. Howe AND J. A. MerCER. 2004. Acoustic and satellite remote sensing of blue whale seasonality and habitat in the Northeast Pacific. Deep-Sea Research II 51:967-986.

CALAMBOKIDIS, J., AND J. BARLOW. 2004. Abundance of blue and humpback whales in the eastern North Pacific estimated by capture-recapture and line-transect methods. Marine Mammal Science 20:63-85. 
Calambokidis, J., G. H. Steiger, J. C. Cubbage, K. C. Balcomb, E. Ewald, S. Kruse, R. WELlS AND R. SEARS. 1990. Sightings and movements of blue whales off central California 1986-88 from photo-identification of individuals. Report of the International Whaling Commission (Special Issue 12):343-348.

Carretta, J. V., M. S. Lowry, C. E. Stinchcomb, M. S. Lynn and R. E. Cosgrove. 2000. Distribution and abundance of marine mammals at San Clemente Island and surrounding offshore waters: Results from aerial and ground surveys in 1998 and 1999. National Marine Fisheries Service Southwest Fisheries Science Center Administrative Report LJ-00-02. 44 pp. Available from SWFSC, P. O. Box 271, La Jolla, CA 92038.

Clark, C. W., AND K. M. Fristrup. 1997. Whales '95: A combined visual and acoustic survey of blue and fin whales off southern California. Report of the International Whaling Commission 47:583-599.

Croll, D. A., B. R. Tershy, R. P. Hewitt, D. A. Demer, P. C. Fiedler, S. E. Smith, W. Armstrong, J. M. Popp, T. Kiekhefer, V. R. Lopez, J. Urban R. and D. Gendron. 1998. An integrated approach to the foraging ecology of marine birds and mammals. Deep-Sea Research 45:1353-1371.

DAWBIN, W. H. 1997. Temporal segregation of humpback whales during migration in southern hemisphere waters. Memoirs of the Queensland Museum 42:105-138.

EFron, B., AND R. J. TIBSHIRANI. 1998. An introduction to the bootstrap. Chapman and Hall/CRC, New York, NY.

FERGUSON, M. C., AND J. BARLOW. 2001. Spatial distribution and density of cetaceans in the eastern Pacific Ocean based on summer/fall research vessel surveys in 1986-1996. National Marine Fisheries Service Southwest Fisheries Science Center Administrative Report LJ-01-04. 61 pp. Available from SWFSC, P. O. Box 271, La Jolla, CA 92038.

Ferguson, M. C., J. Barlow, P. C. Fiedler, S. B. Reilly and T. Gerrodette. 2006. Spatial models of delphinid (family Delphinidae) encounter rate and group size in the eastern tropical Pacific Ocean. Ecological Modelling 193:645-662.

FORNEY, K. A. 2000. Environmental models of cetacean abundance: Reducing uncertainty in population trends. Conservation Biology 14:1271-1286.

FORNEY, K. A., AND J. BARLOW. 1998. Seasonal patterns in the abundance and distribution of California cetaceans, 1991-1992. Marine Mammal Science 14:460-489.

HAstie, T. J., AND R. J. TibshiRANi. 1990. Generalized additive models. Chapman and Hall, New York, NY.

KASS, R. E., AND A. E. RAFERTY. 1995. Bayes factors. Journal of the American Statistical Association 90:773-795.

LARKMAN, V. E., AND R. R. VEIT. 1998. Seasonality and abundance of blue whales off Southern California. CalCOFI Reports 39:236-239.

Mate, B. R., B. A. LAgerquist And J. Calambokidis. 1999. Movements of North Pacific blue whales during the feeding season off southern California and their southern fall migration. Marine Mammal Science 15:1246-1257.

MCDONALD, M. A. 2004. DIFAR hydrophones applied to whale research. Canadian Journal of Acoustics 32:155-160.

McDonald, M. A., J. Calambokidis, A. M. Teranishi and J. A. Hildebrand. 2001. The acoustic calls of blue whales off California with gender data. Journal of the Acoustical Society of America 109:1728-1735.

MELLINGER, D. K. 2002. ISHMAEL: Integrated system for holistic multi-channel acoustic exploration and localization. NOAA Technical Memorandum OAR PMEL-120. 30 pp. Available from Pacific Marine Environmental Laboratory, Newport, OR.

MELLINGER, D. K., AND J. BARLOW. 2003. Future directions for acoustic marine mammal surveys: Stock assessment and habitat use. Report of a Workshop held in La Jolla, CA, 20-22 November 2002. NOAA OAR Special Report, NOAA/PMEL Contribution No. 2557. 37 pp. Available from NOAA/Pacific Marine Environmental Laboratory, Newport, OR. 
Oleson, E. M., J. Calambokidis, W. C. Burgess, M. A. McDonald, C. A. LeDuC and J. A. Hildebrand. 2007. Behavioral context of call production by eastern North Pacific blue whales. Marine Ecology Progress Series 330:269-284.

Oleson, E. M., S. M. Wiggins AND J. A. Hildebrand. In press. Temporal separation of blue whale call types on a southern California feeding ground. Animal Behaviour.

PAYNE, R., AND S. MCVAY. 1971. Songs of humpback whales. Science 173:585-597.

RANKIN, S., D. LJungBlad, K., C. W. Clark AND H. KATO. 2005. Vocalisations of Antarctic blue whales, Balaenoptera musculus intermedia, recorded during the 2001/2002 and 2002/2003 IWC/SOWER circumpolar cruises, Area V, Antarctica. Journal of Cetacean Research and Management 7:13-20.

Rice, D. W., And A. A. Wolman. 1971. The life history and ecology of the gray whale (Eschrichtius robustus). Special Publication of The American Society of Mammologists, No. 3. 142 pp.

Širović, A., J. A. Hildebrand AND D. Thiele. 2006. Baleen whales in the Scotia Sea during January and February 2003. Journal of Cetacean Research and Management 8:161-171.

SOKAL, R. R., AND F. J. ROHLF. 1981. Biometry: The principles and practice of statistics in biological research. W. H. Freeman and Company, San Francisco, CA.

StAFFORD, K. M., S. L. NieUKIRK AND C. G. FOX. 2001. Geographic and seasonal variation of blue whale calls in the North Pacific. Journal of Cetacean Research and Management 3:65-76.

Swartz, S. L., T. Cole, M. A. McDonald, J. A. Hildebrand, E. M. Oleson, A. MarTINEZ, P. J. Clapham, J. BARLOW AND M. L. JONES. 2003. Acoustic and visual survey of humpback whale (Megaptera novaeangliae) distribution in the eastern and southern Caribbean Sea. Caribbean Journal of Science 39:195-208.

Thode, A. M., G. L. D'Spain And W. A. Kuperman. 2000. Matched-field processing, geoacoustic inversion, and source signature recovery of blue whale vocalizations. Journal of the Acoustical Society of America 107:1286-1300.

ThOmAS, J. A., S. R. FisHer AND L. A. Ferm. 1986. Acoustic detection of cetaceans using a towed array of hydrophones. Report of the International Whaling Commission (Special Issue 8):139-147.

Urick, R. J. 1983. Principles of underwater sound. Peninsula Publishing, Los Altos, CA.

Watkins, W. A., M. A. Daher, G. M. Reppucci, J. E. George, D. L. Martin, N. A. DiMARZIO AND D. P. GANNON. 2000. Seasonality and distribution of whale calls in the North Pacific. Oceanography 13:62-67.

Received: 21 June 2006 Accepted: 26 January 2007 